OPEN ACCESS

Edited by:

Elysa Jill Marco,

Cortica (United States), United States

Reviewed by:

Angel Nunez,

Autonomous University of Madrid,

Spain

Michelle Stephens, Independent Researcher,

San Francisco, United States

*Correspondence:

Connie Lillas

infantmentalhealth1954@gmail.com

Received: 31 October 2019

Accepted: 29 January 2020

Published: 18 February 2020

Citation:

Christensen JS, Wild H, Kenzie ES, Wakeland W, Budding D and Lillas C (2020) Diverse Autonomic Nervous System Stress Response Patterns in

Childhood Sensory Modulation.

Front. Integr. Neurosci. 14:6. doi: 10.3389/fnint.2020.00006

\section{Diverse Autonomic Nervous System Stress Response Patterns in Childhood Sensory Modulation}

\author{
Jacquelyn S. Christensen ${ }^{1}$, Heather Wild ${ }^{2}$, Erin S. Kenzie ${ }^{3}$, Wayne Wakeland ${ }^{3}$, \\ Deborah Budding ${ }^{4}$ and Connie Lillas ${ }^{5 *}$
}

${ }^{1}$ Department of Psychology, Pitzer College, Claremont, CA, United States, ${ }^{2}$ Psychology Program, Portland State University, Portland, OR, United States, ${ }^{3}$ Systems Science Program, Portland State University, Portland, OR, United States,

${ }^{4}$ Harbor-UCLA Medical Center, Los Angeles, CA, United States, ${ }^{5}$ NeuroRelational Framework (NRF) Institute, Pasadena, CA, United States

The specific role of the autonomic nervous system (ANS) in emotional and behavioral regulation-particularly in relation to automatic processes-has gained increased attention in the sensory modulation literature. This mini-review article summarizes current knowledge about the role of the ANS in sensory modulation, with a focus on the integrated functions of the ANS and the hypothalamic-pituitary-adrenal (HPA) axis and their measurement. Research from the past decade illustrates that sympathetic and parasympathetic interactions are more complex than previously assumed. Patterns of ANS activation vary across individuals, with distinct physiological response profiles influencing the reactivity underlying automatic behavioral responses. This review article advances a deeper understanding of stress and the complex stress patterns within the ANS and HPA axis that contribute to allostatic load (AL). We argue that using multiple physiological measurements to capture individual ANS response variation is critical for effectively treating children with sensory modulation disorder (SMD) and sensory differences. We consider the relative contributions of automatic vs. deliberately controlled processes across large-scale neural networks in the development of sensorimotor function and their associated links with arousal patterns and sensory over- and under-responsivity.

Keywords: autonomic nervous system, sensory modulation, stress response, physiological arousal, automatic processes, complex systems, large-scale network, allostatic load

\section{INTRODUCTION}

Sensory modulation is commonly defined as the ability to regulate and organize reactions to sensations in a graded and adaptive manner (Ayres, 1972; Royeen and Lane, 1991; Parham and Mailloux, 1996; Brown et al., 2019). Yet, the occupational therapy community has grappled with various definitions which bifurcate internal neurophysiological arousal and external behavioral responses to stimuli (Miller et al., 2001, 2007; May-Benson and Schaaf, 2015; Brown et al., 2019). Embedded within the definition of sensory modulation disorder (SMD), a subtype of sensory processing disorder (SPD), is the reference to an individual's atypical physiological or behavioral responses to everyday stimuli (McIntosh et al., 1999). Physiologically, SMD has historically been considered to reflect disruption in the mechanisms of habituation and sensitization within the central nervous system (CNS; 
Kandel, 1991). Behaviorally, atypical external responses associated with SMD have been generally categorized as either hyper/over-responsive or hypo/under-responsive as compared to expected response intensity (McIntosh et al., 1999; Miller et al., 2007). However, early observations by Ayres (1963, 2005) posited that children's disruptions with sensory over-responsivity (SOR) were manifestations of "fight-flight" responses from the autonomic nervous system (ANS) to typical, non-aversive stimulation, suggesting a connection between physiological arousal and behavior. Physiological arousal is simply defined as reflecting a continuum of states of alertness across the sleep-wake cycle (Brazelton, 1973; Barnard, 1999; Oken et al., 2006). It is also more elegantly described as a property distributed across autonomic, sensory, emotional, and motor domains (Pfaff and Banavar, 2007; Mendes, 2016). This latter definition affords a multi-dimensional, non-linear approach to integrating concepts of arousal and sensory responsivity.

The relation between ANS arousal, automatic processes, and sensory responsivity has received increased attention in the sensory modulation literature over the last 25 years (Miller et al., 2009). These research studies attempt to explore connections between external behavioral and internal physiological responses to sensory stimulation, though results are mixed. While children often present clinically with concomitant signs of over-responsivity with heightened arousal and likewise, underresponsivity with lower arousal (Lane, 2002; Schoen et al., 2009), some research finds that physiological arousal and behavioral responsivity are uncoupled (Quas et al., 2000) or mixed (Roubinov et al., 2019).

Multiple contributing factors potentially underlie this inconsistent evidence, including the prevalent use of different, yet singular measures not fully representing the complexity of the stress response system (for full review, see Gomez et al., 2017). Inspired by Gomez et al.'s (2017) larger systematic review, we examine how complex stress and stress recovery models have been researched in isolation, and we review how this fragmentation is paralleled in SMD-focused research. Current neuroscientific approaches featuring large-scale networks, dual-tiered processes and computer modeling offer possibilities to facilitate a more nuanced understanding of physiological variances in arousal and sensory responsivity (Cisek, 2019; Schmahmann et al., 2019). Applying complexity-informed approaches to address the heterogeneity in stress and allostatic load (AL) continuums complement the current shift away from discrete Diagnostic Statistical Manual of Mental Disorders (DSM) diagnostic categories in favor of multidimensional and overlapping processes underlying many disorders. This review article offers recommendations regarding integrated approaches to both SMD research and clinical intervention.

\section{STRESS MODELS AND AROUSAL IN SENSORY MODULATION DISORDER: FROM SIMPLE TO COMPLEX}

The following sections describe elements of the ongoing evolution of ANS stress models and their frequent use of limited biomarkers. Many SMD pediatric studies rely solely on parent-completed behavioral checklists to measure sensory responsivity. This review article, however, focuses on SMD studies that also include at least one physiological measure in the context of the Sensory Challenge Protocol (SCP; McIntosh et al., 1999; Miller et al., 1999). This laboratory-based protocol provides a standardized procedure for administering a range of stimuli, which evaluates a child's physiological arousal reactivity (for reviews of sensory measurements, see Schaaf et al., 2014; Jorquera-Cabrera et al., 2017).

\section{Sympathetic Nervous System and HPA Axis: Historical Views of Stress and Allostatic Load}

Models of stress physiology have historically defined stress response systems as comprising forces of activation and inhibition between two branches of the ANS: the sympathetic nervous system (SNS) and the parasympathetic nervous system (PNS; McEwen, 1998, 2017). The SNS instantiates the fightor-flight response associated behaviorally with high-intensity motoric mobilization, while the PNS is considered the "restand-digest" division of the ANS. Unfamiliar or noxious stimuli can result in simultaneous activation of the SNS and stimulation of the hypothalamic-pituitary-adrenocortical (HPA) axis. Increased amounts of cortisol are subsequently released into the bloodstream, in concert with the restorative response of the PNS, with both facilitating stress recovery (Gunnar and Quevedo, 2007; McEwen, 2007).

Per models grounded in allostatic regulation, when dysregulation prevails within the SNS-HPA axis system, associated neurophysiological responses shift to prolonged activation, inhibition, or both, impacting multiple organ systems (Gunnar and Quevedo, 2007; McEwen, 2007). These subsequent arousal patterns involve temporal dimensions of frequency, duration, and intensity of physiological responses that can go awry, at times accompanied by habituation failures (McEwen, 1998). Resultant wear and tear on the body and brain, impacting both physiological and psychological functioning, is termed AL (see Table 1; e.g., McEwen, 1998, 2017; Goldstein and McEwen, 2002; Berens et al., 2017). These internal arousal patterns often parallel the external behavioral mismatches in grading and regulating the degree and intensity of responses to sensory information that define SMDs (Miller et al., 2007).

Primary biomarkers of SNS activity used in the pediatric stress and SMD literature include a pre-ejection period (PEP) and electrodermal activity (EDA). Derived via analysis of electrocardiogram (ECG) data, PEP promotes the use of a singular organ (heart) to examine the synchronicity between the SNS and PNS. Though it is more robust in laboratory settings (Bush et al., 2011, 2016; Schaaf et al., 2015), PEP may be a less sensitive biomarker of SNS compared to other measures in pediatric studies (Roder et al., 2020). Alternatively, EDA measures the conductivity of the skin that results from changes in sweat gland activity (Fowles, 1986) and is well-established as a marker of physiological SNS arousal particularly related to psychological distress (El-Sheikh, 2007; 
Gatzke-Kopp and Ram, 2018). It is predominantly used to capture variability in physiological sympathetic arousal in the SMD literature (Gomez et al., 2017).

Generally, greater frequency and magnitude of EDA to either all or specific sensory stimulation was observed in the SNS-focused SMD studies reviewed, illustrating that these temporal dimensions were recurrent regardless of diagnosis (see Table 2). While habituation occurred in one study (Schoen et al., 2009), children habituated more slowly in two samples (McIntosh et al., 1999; Su et al., 2010) and fewer children habituated in another (Miller et al., 1999). In addition, a few children with no EDA response to stimulation were reported (McIntosh et al., 1999; Schoen et al., 2009). Most of the reviewed studies found coupling between the reports of external behaviors of SMD and physiological reactivity, and when there was not a match, the higher or lower arousal reactivity remained present. The higher and lower arousal patterns found in SMD implicates sympathetic arousal impairments that may indicate $\mathrm{AL}$ conditions, prompting the need for longitudinal naturalistic studies.

Several SMD-focused studies explored the HPA axis, which modulates ANS activity, by including salivary cortisol collection in their protocols. In a small pilot study, SOR was examined as a moderator of HPA activity in children diagnosed with attention-deficit/hyperactivity disorder (ADHD; Reynolds et al., 2010). Children with ADHD and SOR displayed similar cortisol patterns to typically developing children, while children with ADHD without SOR displayed lower, possibly blunted, cortisol responses (Reynolds et al., 2010). While blunted cortisol is frequently observed in children with ADHD (Ma et al., 2011; Pinto et al., 2016), it is also observed in individuals with early adversity (Bunea et al., 2017; Kuras et al., 2017), illustrating the complex relationship between sensory modulation and stress arousal patterns. Emerging models of HPA reactivity also support various trajectories of "typical" daily cortisol patterns (Van Ryzin et al., 2009). In a larger study that did use more than one physiological measure (EDA and cortisol), Lane et al. (2010) found that the combined measures in conjunction with trait anxiety scores were more predictive of children's SOR scores than any of these indicators alone, supporting the need to use multiple markers to have a more complete picture of arousal and reactivity. Complex variations in cortisol patterns support exploring within-person differences, furthering the investigation of heterogeneity in multifaceted allostatic arousal patterns within SMD (Gatzke-Kopp and Ram, 2018). Stress response models solely considering solely sympathetic and HPA axis activation via EDA or cortisol collection are limited in that they fail to capture the complexity of the ANS, including the role of the PNS.

\section{Parasympathetic Nervous System Focus}

The PNS was historically considered to counterbalance SNS activation, conserving energy as the vagus nerve slows heart rate, facilitating digestion by increasing intestinal activity and relaxing sphincter muscles in the gastrointestinal tract (Browning et al., 2017). The Polyvagal Theory describes two branches of the PNS (Porges, 2001, 2007). The first branch of the vagus nerve comprises the myelinated ventral vagal brake, which 
TABLE 2 | Selected SMD articles by stress response model and physiological patterns.

\begin{tabular}{|c|c|c|c|c|c|}
\hline Study & Sample age & Diagnosis (n) & $\begin{array}{l}\text { Physiological } \\
\text { measurement }\end{array}$ & $\begin{array}{l}\text { Activation patterns of } \\
\text { physiology }\end{array}$ & $\begin{array}{l}\text { Inhibition patterns of } \\
\text { physiology }\end{array}$ \\
\hline \multicolumn{6}{|c|}{ Stress Model: SNS and HPA Axis Focus } \\
\hline Miller et al. (1999) & $4-49$ & $\begin{array}{l}\text { Fragile } \times \text { Syndrome }(15) \\
\text { Fragile } \times \text { Mutation }(25)\end{array}$ & $\begin{array}{l}\text { EDA } \\
\text { (for SNS) }\end{array}$ & $\begin{array}{l}\text { Greater EDA frequency and } \\
\text { magnitude; Lower habituation rate }\end{array}$ & - \\
\hline $\begin{array}{l}\text { Mclntosh et al. } \\
\text { (1999) }\end{array}$ & $3-9$ & $\begin{array}{l}\text { SMD (19) } \\
\operatorname{TYP}(19)\end{array}$ & $\begin{array}{l}\text { EDA } \\
\text { (for SNS) }\end{array}$ & $\begin{array}{l}\text { Greater EDA frequency and } \\
\text { magnitude; Lower habituation rates }\end{array}$ & $\begin{array}{l}\text { No EDA response to stimulation } \\
(n=4)\end{array}$ \\
\hline $\begin{array}{l}\text { Mangeot et al. } \\
\text { (2001) }\end{array}$ & $5-13$ & $\begin{array}{l}\text { ADHD (26) } \\
\text { TYP (30) }\end{array}$ & $\begin{array}{l}\text { EDA } \\
\text { (for SNS) }\end{array}$ & $\begin{array}{l}\text { Greater EDA magnitude (early } \\
\text { response to sensations) }\end{array}$ & - \\
\hline Schoen et al. (2009) & $4-15$ & $\begin{array}{l}\text { SMD (31) } \\
\text { ASD (38) } \\
\text { TYP (33) }\end{array}$ & $\begin{array}{l}\text { EDA } \\
\text { (for SNS) }\end{array}$ & $\begin{array}{l}\text { Greater response arousal of EDA } \\
\text { (1st trial of sensory stimulation) } \\
\text { (SMD); Greater EDA magnitude and } \\
\text { amplitude (SMD); Habituation } \\
\text { occurred }\end{array}$ & $\begin{array}{l}\text { Lower arousal at baseline (ASD) } \\
\text { No EDA response to stimulation } \\
\text { found } 20-35 \% \text { of each subgroup }\end{array}$ \\
\hline Su et al. (2010) & $4-8$ & $\begin{array}{l}\text { SMD (14) } \\
\operatorname{TYP}(17)\end{array}$ & $\begin{array}{l}\text { EDA } \\
\text { (for SNS) }\end{array}$ & $\begin{array}{l}\text { Greater EDA frequency and } \\
\text { magnitude; } \\
\text { Slower habituation }\end{array}$ & - \\
\hline Miller et al. (2012) & $6-12$ & $\begin{array}{l}\text { SMD (37) } \\
\text { ADHD (28) } \\
\text { SMD and ADHD (12) } \\
\text { TYP (30) }\end{array}$ & $\begin{array}{l}\text { EDA } \\
\text { (for SNS) }\end{array}$ & $\begin{array}{l}\text { Greater EDA magnitude (SMD vs. } \\
\text { ADHD and TYP) }\end{array}$ & 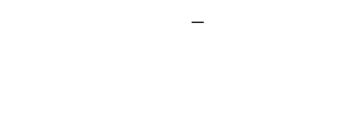 \\
\hline $\begin{array}{l}\text { Reynolds et al. } \\
\text { (2010) }\end{array}$ & $6-12$ & $\begin{array}{l}\text { ADHD w/ SMD (13) } \\
\text { ADHD w/o SMD (11) } \\
\text { TYP (24) }\end{array}$ & $\begin{array}{l}\text { Salivary Cortisol } \\
\text { (for HPA axis) }\end{array}$ & - & $\begin{array}{l}\text { Blunted cortisol response (ADHD } \\
\text { w/o SMD) }\end{array}$ \\
\hline Lane et al. (2010) & $6-12$ & $\begin{array}{l}\text { ADHD (18); } \\
\text { TYP (36); } \\
\text { ADHD w SOR (21); } \\
\text { TYP w SOR (9) }\end{array}$ & $\begin{array}{l}\text { EDA (for SNS) } \\
\text { Salivary Cortisol } \\
\text { (for HPA axis) }\end{array}$ & $\begin{array}{l}\text { Twice as many non-specific EDA } \\
\text { spikes post a challenge, during the } \\
\text { recovery phase (ADHD w/ SOR) } \\
\text { Elevated cortisol post a challenge } \\
\text { (TYP and ADHD with SOR) }\end{array}$ & - \\
\hline \multicolumn{6}{|c|}{ Stress Models: PNS Focus } \\
\hline Schaaf et al. (2003) & $4-8$ & $\begin{array}{l}\text { SMD (9) } \\
\text { TYP (6) }\end{array}$ & $\begin{array}{l}\text { HRV } \\
\text { (for PNS) }\end{array}$ & - & $\begin{array}{l}\text { Significantly lower cardiac vagal } \\
\text { tone } \\
\text { Lower heart period }\end{array}$ \\
\hline Schaaf et al. (2010) & $5-12$ & $\begin{array}{l}\text { TYP (40); } \\
\text { Severe SMD (15); } \\
\text { Moderate SMD (13) } \\
\text { Borderline SMD (11) }\end{array}$ & $\begin{array}{l}\text { HRV } \\
\text { (for PNS) }\end{array}$ & - & $\begin{array}{l}\text { Severe SMD-lower mean vagal } \\
\text { tone during baseline, tones, and } \\
\text { prolonged auditory stimulation }\end{array}$ \\
\hline
\end{tabular}

Stress Models: SNS and PNS Focus

No studies specific to SMD done at this time with both biomarkers

Note: All studies included used Sensory Challenge Protocol (SCP). SMD, Sensory modulation disorder; TYP, Typical; ADHD, Attention-deficit/hyperactivity disorder; EDA, Electrodermal activity; HRV, Heart-rate Variability; SNS, Sympathetic nervous system; PNS, Parasympathetic nervous system; HPA-axis, Hypothalamic-pituitary-adrenal axis. 
modulates heart rate to encourage calm engagement with sensory or relational stimulation. The second branch comprises the unmyelinated dorsal vagal brake, which contributes to the freeze stress response and influences under-responsive and less reactive stress patterns. For example, varying degrees of the behavioral shutdown and motoric immobilization are clinically associated with an under-responsive continuum of depression, dissociation, and fainting, including bradycardia (Porges, 2004, 2009).

Measures of PNS activity are typically derived through ECG, and include heart rate variability (HRV) and respiratory sinus arrhythmia (RSA). Controversy exists regarding the interpretation of HRV measurement output given the complexity and nonlinearity of sympathetic and parasympathetic interactions (for full review, see Laborde et al., 2017). Earlier research regarding the implications of poor vagal tone on regulation, including sleep, feeding, self-soothing, and behavioral challenges (Degangi et al., 1991; Porges et al., 1996), supported the shift in SMD research to consider how poor parasympathetic functioning impacts stress vulnerability and SOR, possibly providing better insight to ANS functioning (Schaaf et al., 2003). In a small pilot study aligned with Porges's research, children with SMD showed significantly lower cardiac vagal tone than typically developing children (Schaaf et al., 2003). In subsequent research, children with severe SMD displayed lower PNS activity than typically developing children during the use of the SCP, including during prolonged auditory stimulation (Schaaf et al., 2010). In children with SMD as compared to typically developing children, parasympathetic reactivity was found to couple with extreme sensory over- and under-responsivity (Schaaf et al., 2003) and poorer adaptive behavior (Schaaf et al., 2010). These results imply that children with SMD are impacted by both a diminished sympathetic system and parasympathetic impairments that contribute to poor arousal and behavioral adaptations to sensations, possibly contributing to AL conditions. Yet, these studies do not include robust integration of the HPA axis, nor direct measurement of the SNS or capture the nonlinearity of the ANS.

\section{Sympathetic and Parasympathetic Focus}

Traditionally, the SNS is thought to cause activation of the physiological structures it innervates, while the PNS inhibits these same structures in a mutually oppositional fashion. The doctrine of autonomic space asserts that the interaction between sympathetic and parasympathetic branches of the nervous system is not solely inhibitory in nature and that autonomic control is dynamic and synchronous (see Table 1; Berntson et al., 1994; Berntson and Cacioppo, 2004). Berntson and Cacioppo (2004) proposed nine possible interactions within patterns of coupled (including coactivation and co-inhibition), reciprocal, and uncoupled activation and inhibition (independent) within SNS and PNS branches (Berntson et al., 1991, 1993; Koizumi and Kollai, 1992). Others exploring patterns within autonomic space using both SNS and PNS biomarkers found combinations of coupled and reciprocal stress response patterns, concluding that standard stress models often fail to capture such variability (Salomon et al., 2000; Rotenberg and McGrath, 2016; Brush et al., 2019).
To date, SMD-focused research has not used multiple measures to track simultaneous SNS-PNS interaction, though related research focused on sensory differences in autism and ADHD populations have used multiple physiological markers with findings that reveal inconsistent stress patterns supporting heterogeneity in ANS-HPA axis functions (Lane et al., 2010; Schaaf et al., 2015).

\section{Progression Towards Heterogeneity in Stress Response Patterns}

Recent stress research examines heterogeneous stress response patterns by including multiple facets of the ANS-HPA axis (Del Giudice et al., 2011; Quas et al., 2014). The adaptive calibration model, based on biological sensitivity to context theory, aimed to capture heterogeneity through four proposed stress response patterns based on measures of SNS, PNS, and HPA reactivity (Del Giudice et al., 2012). Quas et al. (2014) empirically examined this more nuanced picture of stress response patterns via secondary data analysis of four independent studies. These data include PEP, HRV, and cortisol collected at baseline and in response to stimulation. This analysis yielded six distinct profiles of stress reactivity, adding complexity to aforementioned coupled, reciprocal, and uncoupled patterns (see Table 1). While some SMD-focused research also attempts to capture categorical differences (e.g., Schaaf et al., 2010), no studies of SMD have yet implemented this latest approach to stress response research by accounting for multiple biomarkers and patterns of stress reactivity in typical and neurodiverse populations. This approach would deepen our understanding of heterogeneity in stress arousal patterns with the potential for recognizing AL conditions existing within SMD.

\section{LARGE-SCALE NETWORKS AND DUAL-TIERED MODELS}

While physiologic reactivity does not always correlate directly with the behavioral response, it does provide an indication that internal levels of arousal and stress are connected to emotional, behavioral, social, and health outcomes (LeDoux and Hofmann, 2018). Widely distributed neural networks developed over millions of years across species help manage our continual process of environmental interaction and exposure to sensory information by maximizing automatized processes (Cisek and Kalaska, 2010; Cisek, 2019). Automatic processes and behaviors are those performed implicitly, while deliberate processes and behaviors are those performed explicitly, although these exist on a continuum and are rarely discrete (Boraud et al., 2018; LeDoux and Daw, 2018). Dual-tier models of automatic vs. deliberate processes and behavior in conjunction with large-scale network functions provide further means of conceptualizing the relationship between internal stress physiology, sensory responsivity, and external behavior.

Two large-scale networks have been presented as contributing to the development of automatic or habitual emotional and behavioral responses. Cerebro-cerebellar and Cerebro-striatalthalamic circuitry are particularly relevant to sensorimotor development, providing essential regulatory functions in 
information processing across distributed networks, including autonomic, sensorimotor, affective, and cognitive domains (Koziol et al., 2011, 2012; Shine and Shine, 2014; Schmahmann et al., 2019). The cerebellum potentially plays a central role in which processes become automatic and related circuits are thought to contribute to the gradation of rate, rhythm, and force involved in motor or behavioral modulation challenges resulting in "over-shooting" and "under-shooting" target behaviors often seen in occupational and neurological clinical settings (Engel-Yeger, 2019). For example, the slower and lower rates of habituation reported in several SMD-EDA focused studies (see Table 2) can be viewed through this automaticity-relevant largescale network lens, and it is consistent with the aforementioned definition of SMD as an inability to grade responses to sensation (Ayres, 1972; Royeen and Lane, 1991; Parham and Mailloux, 1996; Brown et al., 2019). Both Cerebro-cerebellar and Cerebrostriatal-thalamic circuitries are active in mobilizing arousal responses to sensations experienced as threatening. Their complex interactions can contribute to sensitization, which is an increase in arousal reactivity with exposure to the same stimuli, as well as the more typically expected habituation, which is a decrease of arousal with repeated exposure. Sensitization can be found underlying multiple diagnostic categories including autism and trauma-related syndromes (De Bellis and Zisk, 2014; Sinclair et al., 2017).

Additionally, theories of generalized arousal of the CNS (Pfaff and Banavar, 2007; Quinkert et al., 2011; Calderon et al., 2016) propose that arousal reactivity, emotional processes (Tops et al., 2017), and sensory responsivity (Deneve and Pouget, 2004; Olcese et al., 2018), in concert with motor activation (Torres and Whyatt, 2018; Wu et al., 2018), can be considered ongoing, parallel, intersecting processes with automaticity. For example, the neurovisceral integration model (NVI; Thayer and Lane, 2000), spans automatic and deliberate processes (Smith et al., 2016), providing emerging neuroanatomical and experimental support (from rodents and primates) for a variety of distributed control networks supporting the integration of autonomic, emotional, attentional, and cognitive information. To best explore the complex, integrated relationships between temporal dynamics across various large-scale networks, nonlinear approaches and computational modeling are used (Wiley et al., 2016; Shine et al., 2019).

\section{CONCLUSION}

While many stress models call for a more complex view of physiological stress responses, none until recently have described interactions between more than two physiological branches of the ANS-HPA axis (Quas et al., 2014). This fragmentation and associated dominance of singular physiological biomarkers in both stress model-related and SMD-focused research constrain advancement in both fields towards greater complexity and heterogeneity. Large-scale network models offer several possible frameworks capable of managing the highly complex physiological and behavioral aspects of both stresses- and SMD-related research. First, the multiple reactivities and patterns of arousal should be studied in a more complex and coordinated manner. However, in line with earlier reviews (e.g., Rogers and Ozonoff, 2005; Gomez et al., 2017), we highlight the variability in children's ANS-HPA axis responses to sensory stimuli, regardless of diagnosis. We view this heterogeneity as a natural and expected continuum of arousal occurring across individual nervous systems. Aligning with NIMH Research Domain Criteria (RDoC; Sanislow et al., 2019), SMD can be viewed as an integral aspect of stress response physiology, providing an underlying dimension to join other categorical diagnostic entities formerly considered discrete. This supports work wherein SMD is expanded beyond neurodiverse populations, and considered an essential means of accessing evidence of autonomic dysregulation characteristic of various populations with vulnerable nervous systems, including individuals with prematurity, mental health diagnosis, or early adversity (Shonkoff et al., 2012; Paul-Ward and LambdinPattavina, 2016; Pears et al., 2016; Andersen et al., 2018; Germain, 2018; Machingura et al., 2018; Brown et al., 2019; Mulkey and du Plessis, 2019).

Second, large scale network models emphasize measuring multiple processes and temporal dimensions occurring across physiological biomarkers. Evidence within SMD and stress research suggests that each biomarker, including EDA, PEP, cortisol, and HRV, can display coupled, reciprocal, and uncoupled activation patterns. These patterns occur in varying frequency, intensity, periodicity, rhythm, and duration. These temporal dimensions can match or mismatch associated context resulting in a heightened or dampened stress response. Further study of ANS-HPA axis heterogeneity as potential indicators of AL patterns (McEwen, 1998) requires simultaneous use of three or more physiological markers across multiple time scales in a variety of settings, more closely representing behavior observed outside of laboratory settings. We suggest that future SMD and stress arousal-focused research track both the external behavioral responses and internal physiological reactivity by capturing ANS-HPA axis activation-inhibition in both short-term and longitudinal time scales. As research-quality wearable sensors become more accessible, integrated arousal and SMD studies can move from the laboratory to community settings to further illuminate the variety of internal and external mismatches that can occur in daily occupations. Thus, non-linear dynamical models are most appropriate for managing the varying temporal dynamics related to ANS-HPA axis systems. Complex systems modeling, which strives to portray causal interrelationships within a system, has been used to generate insight into a wide range of biomedical applications (Wittenborn et al., 2016; Kenzie et al., 2018) and could be advantageous. Finally, automatic and deliberate processes from dual-tiered models inform effective treatment planning by supporting the alignment of treatment approaches across distributed systems. Integrating awareness of arousal regulation with sensorimotor-based treatments are necessary, including a promising trend towards decreasing EDA magnitude (e.g., Miller et al., 2007; Bodison and Parham, 2018; Foitzik and Brown, 2018). Sensorimotor-focused treatment strategies can impact a variety of distributed properties and benefit from being coupled with socio-emotional and play-based 
relational approaches (Greenspan et al., 1998; Bundy et al., 2008; Lillas et al., 2018; Pfeiffer et al., 2018; Roberts et al., 2018; Schaaf et al., 2018; Delahooke, 2019; Porges et al., 2019). This integrated, interdisciplinary lens better addresses sensorimotor over- and under-responsivity in tandem with the arousal and emotional dysregulation related to internal stress responses.

\section{AUTHOR CONTRIBUTIONS}

JC contributed to the conceptualization, organization, and primary revisions of the manuscript and drafting tables. HW and DB contributed to the manuscript, providing content knowledge. EK and WW contributed to the manuscript. CL took the lead

\section{REFERENCES}

Ayres, A. J. (1963). The development of perceptual-motor abilities: a theoretical basis for treatment of dysfunction. Am. J. Occup. Ther. 17, 221-225.

Ayres, A. J. (1972). Sensory Integration and Learning Disorders. Los Angeles, Calif Western: Psychological Services. Available online at: https://trove.nla.gov.au/version/50603830.

Ayres, A. J. (2005). Sensory Integration and the Child: 25th Anniversary Edition. 1st Edn. Los Angeles, CA: Western Psychological Services.

Andersen, E. H., Lewis, G. F., and Belger, A. (2018). Aberrant parasympathetic reactivity to acute psychosocial stress in male patients with schizophrenia spectrum disorders. Psychiatry Res. 265, 39-47. doi: 10.1016/j.psychres.2018. 04.009

Barnard, K. E., and National Child Assessment Satellite Training Programs. (1999). Beginning Rhythms: The Emerging Process of Sleep Wake Behaviors and Self-Regulation. Seattle: NCAST, University of Washington.

Berens, A. E., Jensen, S. K. G., and Nelson, C. A. (2017). Biological embedding of childhood adversity: from physiological mechanisms to clinical implications. BMC Med. 15:135. doi: 10.1186/s12916-017-0895-4

Berntson, G. G., and Cacioppo, J. T. (2004). "Heart rate variability: stress and psychiatric conditions," in Dynamic Electrocardiography, eds M. Malik and A. J. Camm (Oxford, UK: Blackwell Publishing), 57-64.

Berntson, G. G., Cacioppo, J. T., and Quigley, K. S. (1991). Autonomic determinism: the modes of autonomic control, the doctrine of autonomic space, and the laws of autonomic constraint. Psychol. Rev. 98, 459-487. doi: 10.1037/0033-295x.98.4.459

Berntson, G. G., Cacioppo, J. T., and Quigley, K. S. (1993). Respiratory sinus arrhythmia: autonomic origins, physiological mechanisms, and psychophysiological implications. Psychophysiology 30, 183-196. doi: 10.1111/j. 1469-8986.1993.tb01731.x

Berntson, G. G., Cacioppo, J. T., Quigley, K. S., and Fabro, V. T. (1994). Autonomic space and psychophysiological response. Psychophysiology 31, 44-61. doi: 10.1111/j.1469-8986.1994.tb01024.x

Bodison, S. C., and Parham, L. D. (2018). Specific sensory techniques and sensory environmental modifications for children and youth with sensory integration difficulties: a systematic review. Am. J. Occup. Ther. 72, 7201190040p1-7201190040p11. doi: 10.5014/ajot.2018.029413

Boraud, T., Leblois, A., and Rougier, N. P. (2018). A natural history of skills. Prog. Neurobiol. 171, 114-124. doi: 10.1016/j.pneurobio.2018.08.003

Brazelton, T. B. (1973). Neonatal Behavioral Assessment Scale. Clinics in Developmental Medicine; No. 50. London; Philadelphia: Spastics International Medical Publications: Heinemann Medical; J. B. Lippincott.

Brown, A., Tse, T., and Fortune, T. (2019). Defining sensory modulation: a review of the concept and a contemporary definition for application by occupational therapists. Scand. J. Occup. Ther. 26, 515-523. doi: 10.1080/11038128.2018. 1509370

Browning, K. N., Verheijden, S., and Boeckxstaens, G. E. (2017). The vagus nerve in appetite regulation, mood, and intestinal inflammation. Gastroenterology 152, 730-744. doi: 10.1053/j.gastro.2016.10.046 in the theoretical conceptualization, organization, and writing of the manuscript and offering content to tables. JC and CL supervised the collaboration of the project.

\section{FUNDING}

We gratefully acknowledge financial support from the Portland State University Foundation.

\section{ACKNOWLEDGMENTS}

We would like to thank Sarah Schoen and Greg Lewis for providing content-specific expertise, as well as Anna Smith for helping with the literature organization.

Brush, C. J., Olson, R. L., Ehmann, P. J., Bocchine, A. J., Bates, M. E., Buckman, J. F., et al. (2019). Lower resting cardiac autonomic balance in young adults with current major depression. Psychophysiology 56:e13385. doi: 10.1111/psyp.13385

Bundy, A. C., Luckett, T., Naughton, G. A., Tranter, P. J., Wyver, S. R., Ragen, J., et al. (2008). Playful interaction: occupational therapy for all children on the school playground. Am. J. Occup. Ther. 62, 522-527. doi: 10.5014/ajot.62.5.522

Bunea, I. M., Szentágotai-Tatar, A., and Miu, A. C. (2017). Early-life adversity and cortisol response to social stress: a meta-analysis. Transl. Psychiatry 7:1274 doi: 10.1038/s41398-017-0032-3

Bush, N. R., Alkon, A., Obradović, J., Stamperdahl, J., and Boyce, W. T. (2011). Differentiating challenge reactivity from psychomotor activity in studies of children's psychophysiology: considerations for theory and measurement. J. Exp. Child Psychol. 110, 62-79. doi: 10.1016/j.jecp.2011.03.004

Bush, N. R., Caron, Z. K., Blackburn, K. S., and Alkon, A. (2016). Measuring cardiac autonomic nervous system (ANS) activity in toddlers-resting and developmental challenges. J. Vis. Exp. 108:53652. doi: 10.3791/53652

Calderon, D. P., Kilinc, M., Maritan, A., Banavar, J. R., and Pfaff, D. (2016) Generalized CNS arousal: an elementary force within the vertebrate nervous system. Neurosci. Biobehav. Rev. 68, 167-176. doi: 10.1016/j.neubiorev.2016. 05.014

Cisek, P. (2019). Resynthesizing behavior through phylogenetic refinement. Atten. Percept. Psychophys. 81, 2265-2287. doi: 10.3758/s13414-019-01760-1

Cisek, P., and Kalaska, J. F. (2010). Neural mechanisms for interacting with a world full of action choices. Annu. Rev. Neurosci. 33, 269-298. doi: 10.1146/annurev. neuro.051508.135409

De Bellis, M. D., and Zisk, A. (2014). The biological effects of childhood trauma. Child Adolesc. Psychiatr. Clin. N. Am. 23, 185-222. doi: 10.1016/j.chc.2014. 01.002

Degangi, G. A., Dipietro, J. A., Greenspan, S. I., and Porges, S. W. (1991). Psychophysiological characteristics of the regulatory disordered infant. Infant Behav. Dev. 14, 37-50. doi: 10.1016/0163-6383(91)90053-u

Del Giudice, M., Ellis, B. J., and Shirtcliff, E. A. (2011). The adaptive calibration model of stress responsivity. Neurosci. Biobehav. Rev. 35, 1562-1592. doi: 10.1016/j.neubiorev.2010.11.007

Del Giudice, M., Hinnant, J. B., Ellis, B. J., and El-Sheikh, M. (2012). Adaptive patterns of stress responsivity: a preliminary investigation. Dev. Psychol. 48, 775-790. doi: 10.1037/a0026519

Delahooke, M. (2019). Beyond Behaviors: Using Brain Science and Compassion to Understand Solve Children's Behavioral Challenges. 1st Edn. Eau Claire, WI: PESI Publishing.

Deneve, S., and Pouget, A. (2004). Bayesian multisensory integration and crossmodal spatial links. J. Physiol. Paris 98, 249-258. doi: 10.1016/j.jphysparis.2004. 03.011

El-Sheikh, M. (2007). Children's skin conductance level and reactivity: are these measures stable over time and across tasks? Dev. Psychobiol. 49, 180-186. doi: $10.1002 /$ dev.20171

Engel-Yeger, B. (2019). The involvement of altered sensory modulation in neurological conditions and its relevance to neuro-rehabilitation: a narrative 
literature review. Disabil. Rehabil. 12, 1-10. doi: 10.1080/09638288.2019. 1699175

Foitzik, K., and Brown, T. (2018). Relationship between sensory processing and sleep in typically developing children. Am. J. Occup. Ther. 72, 7201195040p1-7201195040p9. doi: 10.5014/ajot.2018.027524

Fowles, D. C. (1986). "The eccrine system and electrodermal activity," in Psychophysiology: Systems, Processes and Applications, eds M. G. H. Coles, E. Donchin and S. W. Porges (New York, NY: Guilford Press), 51-96.

Gatzke-Kopp, L., and Ram, N. (2018). Developmental dynamics of autonomic function in childhood. Psychophysiology 55:e13218. doi: 10.1111/psyp. 13218

Germain, T. (2018). Finding the body of the mind: integrating occupational therapy's theories of mutual regulation and dysregulation into psychotherapy. J. Infant Child Adolesc. Psychother. 17, 295-309. doi: 10.1080/15289168.2018. 1519756

Goldstein, D. S., and McEwen, B. (2002). Allostasis, homeostats, and the nature of stress. Stress (Amsterdam, Netherlands) 5, 55-58. doi: 10.1080/102538902900012345

Gomez, I. N., Lai, C. Y. Y., Morato-Espino, P. G., Chan, C. C. H., and Tsang, H. W. H. (2017). Behavioural and autonomic regulation of response to sensory stimuli among children: a systematic review of relationship and methodology. Biomed Res. Int. 2017:2629310. doi: 10.1155/2017/2629310

Greenspan, S. I., Wieder, S., and Simons, R. (1998). The Child With Special Needs: Encouraging Intellectual and Emotional Growth. 1st Edn. Reading, Mass: Perseus Books.

Gunnar, M., and Quevedo, K. (2007). The neurobiology of stress and development. Annu. Rev. Psychol. 58, 145-173. doi: 10.1146/annurev.psych.58.110405.085605

Jorquera-Cabrera, S., Romero-Ayuso, D., Rodriguez-Gil, G., and TriviñoJuárez, J.-M. (2017). Assessment of sensory processing characteristics in children between 3 and 11 years old: a systematic review. Front. Pediatr. 5:266. doi: 10.3389/fped.2017.00266

Kandel, E. R. (1991). "Cellular mechanisms of learning and the biological basis of individuality," in Principles of Neural Science, 3rd Edn. eds E. R. Kandel, J. H. Schwartz and T. M. Jessell (Norwalk, CT: Appleton and Lange), 1009-1031.

Kenzie, E. S., Parks, E. L., Bigler, E. D., Wright, D. W., Lim, M. M., Chesnutt, J. C., et al. (2018). The dynamics of concussion: mapping pathophysiology, persistence, and recovery with causal-loop diagramming. Front. Neurol. 9:203. doi: 10.3389/fneur.2018.00203

Koizumi, K., and Kollai, M. (1992). Multiple modes of operation of cardiac autonomic control: development of the ideas from cannon and brooks to the present. J. Auton. Nerv. Syst. 41, 19-29. doi: 10.1016/0165-1838(92)90123-x

Koziol, L. F., Budding, D. E., and Chidekel, D. (2011). Sensory integration, sensory processing, and sensory modulation disorders: putative functional neuroanatomic underpinnings. Cerebellum 10, 770-792. doi: 10.1007/s12311011-0288-8

Koziol, L. F., Budding, D. E., and Chidekel, D. (2012). From movement to thought: executive function, embodied cognition, and the cerebellum. Cerebellum 11, 505-525. doi: 10.1007/s12311-011-0321-y

Kuras, Y. I., Assaf, N., Thoma, M. V., Gianferante, D., Hanlin, L., Chen, X., et al. (2017). Blunted diurnal cortisol activity in healthy adults with childhood adversity. Front. Hum. Neurosci. 11:574. doi: 10.3389/fnhum.2017.00574

Laborde, S., Mosley, E., and Thayer, J. F. (2017). Heart rate variability and cardiac vagal tone in psychophysiological research-recommendations for experiment planning, data analysis, and data reporting. Front. Psychol. 8:213. doi: 10.3389/fpsyg.2017.00213

Lane, S. J. (2002). "Sensory modulation," in Sensory Integration: Theory and Practice, eds A. C. Bundy, S. J. Lane, and E. A. Murray (Philadelphia, PA: FA Davis Company), 101-122.

Lane, S. J., Reynolds, S., and Thacker, L. (2010). Sensory over-responsivity and ADHD: differentiating using electrodermal responses, cortisol, and anxiety. Front. Integr. Neurosci. 4:8. doi: 10.3389/fnint.2010.00008

LeDoux, J., and Daw, N. D. (2018). Surviving threats: neural circuit and computational implications of a new taxonomy of defensive behaviour. Nat. Rev. Neurosci. 19, 269-282. doi: 10.1038/nrn.2018.22

LeDoux, J. E., and Hofmann, S. G. (2018). The subjective experience of emotion: a fearful view. Curr. Opin. Behav. Sci. 19, 67-72. doi: 10.1016/j.cobeha.2017.09. 011
Lillas, C., TenPas, H., Crowley, C., and Spitzer, S. L. (2018). "Improving regulation skills for increased participation for individuals with ASD," in Autism Across the Lifespan: A Comprehensive Occupational Therapy Approach, 4th Edn. eds R. Watling and S. Spitzer (AOTA Press), 319-338.

Ma, L., Chen, Y.-H., Chen, H., Liu, Y.-Y., and Wang, Y.-X. (2011). The function of hypothalamus-pituitary-adrenal axis in children with ADHD. Brain Res. 1368, 159-162. doi: 10.1016/j.brainres.2010.10.045

Machingura, T., Shum, D., Molineux, M., and Lloyd, C. (2018). Effectiveness of sensory modulation in treating sensory modulation disorders in adults with schizophrenia: a systematic literature review. Int. J. Ment. Health Addict. 16, 764-780. doi: 10.1007/s11469-017-9807-2

Mangeot, S. D., Miller, L. J., McIntosh, D. N., McGrath-Clarke, J., Simon, J., Hagerman, R. J., et al. (2001). Sensory modulation dysfunction in children with attention-deficit-hyperactivity disorder. Dev. Med. Child Neurol. 43, 399-406. doi: 10.1017/s0012162201000743

May-Benson, T. A., and Schaaf, R. (2015). "Ayres sensory integration," in International Handbook of Occupational Therapy Interventions, 2nd Edn. ed. I. Söderback (Cham: Springer International Publishing), 633-647.

McEwen, B. S. (1998). Stress, adaptation, and disease: allostasis and allostatic load. Ann. N Y Acad. Sci. 840, 33-44. doi: 10.1111/j.1749-6632.1998.tb09546.x

McEwen, B. S. (2007). Physiology and neurobiology of stress and adaptation: central role of the brain. Physiol. Rev. 87, 873-904. doi: 10.1152/physrev.00 041.2006

McEwen, B. S. (2017). Neurobiological and systemic effects of chronic stress. Chronic Stress doi: 10.1177/2470547017692328 [Epub ahead of print].

McIntosh, D. N., Miller, L. J., Shyu, V., and Hagerman, R. J. (1999). Sensorymodulation disruption, electrodermal responses, and functional behaviors. Dev. Med. Child Neurol. 41, 608-615. doi: 10.1017/s0012162299001267

Mendes, W. B. (2016). Comment: looking for affective meaning in 'multiple arousal' theory: a comment to picard, fedor, and ayzenberg. Emot. Rev. 8, 77-79. doi: 10.1177/1754073914565521

Miller, L. J., McIntosh, D. N., McGrath, A. J., Shyu, V., Lampe, M., Taylor, A. K., et al. (1999). Electrodermal responses to sensory stimuli in individuals with fragile $\times$ syndrome. Am. J. Med. Genet. 83, 268-279. doi: 10.1002/(sici)10968628(19990402)83:4<268::aid-ajmg7>3.0.co;2-k

Miller, L. J., Nielsen, D. M., and Schoen, S. A. (2012). Attention deficit hyperactivity disorder and sensory modulation disorder: a comparison of behavior and physiology. Res. Dev. Disabil. 33, 804-818. doi: 10.1016/j.ridd. 2011.12.005

Miller, L. J., Reisman, J. E., McIntosh, D. N., and Simon, J. (2001). “An ecological model of sensory modulation: performance of children with fragile $\times$ syndrome, autistic disorder, attention-deficit/hyperactivity disorder, and sensory modulation dysfunction," in Understanding the Nature of Sensory Integration with Diverse Populations, eds S. S. Roley, E. I. Blanche and R. C. Schaaf (San Antonio, TX: Therapy Skill Builders), 57-88.

Miller, L. J., Anzalone, M. E., Lane, S. J., Cermak, S. A., and Osten, E. T. (2007). Concept evolution in sensory integration: a proposed nosology for diagnosis. Am. J. Occup. Ther. 61, 135-140. doi: 10.5014/ajot.61.2.135

Miller, L. J., Nielsen, D. M., Schoen, S. A., and Brett-Green, B. A. (2009). Perspectives on sensory processing disorder: a call for translational research. Front. Integr. Neurosci. 3:22. doi: 10.3389/neuro.07.022.2009

Mulkey, S. B., and du Plessis, A. J. (2019). Autonomic nervous system development and its impact on neuropsychiatric outcome. Pediatr. Res. 85, 120-126. doi: 10.1038/s41390-018-0155-0

Oken, B. S., Salinsky, M. C., and Elsas, S. M. (2006). Vigilance, alertness, or sustained attention: physiological basis and measurement. Clin. Neurophysiol. 117, 1885-1901. doi: 10.1016/j.clinph.2006.01.017

Olcese, U., Lohuis, M. N. O., and Pennartz, C. M. A. (2018). Sensory processing across conscious and nonconscious brain states: from single neurons to distributed networks for inferential representation. Front. Syst. Neurosci. 12:49. doi: 10.3389/fnsys.2018.00049

Parham, L. D., and Mailloux, Z. (1996). "Sensory integration," in Occupational Therapy for Children, eds J. Case-Smith, S. Anne Allen, N. Pat Pratt (St. Louis, MO: Mosby), 307-355.

Paul-Ward, A., and Lambdin-Pattavina, C. A. (2016). New roles for occupational therapy to promote independance among youth aging out of foster care. Am. J. Occup. Ther. 70, 7003360010p1-7003360010p5. doi: 10.5014/ajot.2016. 017426 
Pears, K. C., Kim, H. K., and Fisher, P. A. (2016). Decreasing risk factors for later alcohol use and antisocial behaviors in children in foster care by increasing early promotive factors. Child. Youth Serv. Rev. 65, 156-165. doi: 10.1016/j. childyouth.2016.04.005

Pfaff, D., and Banavar, J. R. (2007). A theoretical framework for CNS arousal. Bioessays 29, 803-810. doi: 10.1002/bies.20611

Pfeiffer, B., May-Benson, T. A., and Bodison, S. C. (2018). State of the science of sensory integration research with children and youth. Am. J. Occup. Ther. 72, 7201170010p1-7201170010p4. doi: 10.5014/ajot.2018.721003

Pinto, R., Rijsdijk, F., Ouellet-Morin, I., Asherson, P., McLoughlin, G., and Kuntsi, J. (2016). The etiological association between the dynamics of cortisol productivity and ADHD. J. Neural Transm. 123, 991-1000. doi: $10.1007 / \mathrm{s} 00702-016-1534-5$

Porges, S. W. (2001). The polyvagal theory: phylogenetic substrates of a social nervous system. Int. J. Psychophysiol. 42, 123-146. doi: 10.1016/s0167$8760(01) 00162-3$

Porges, S. W. (2004). The Polyvagal Theory: Neurophysiological Foundations of Emotions, Attachment, Communication, and Self-Regulation (Norton Series on Interpersonal Neurobiology). New York, NY: WW Norton and Company.

Porges, S. W. (2007). The polyvagal perspective. Biol. Psychol. 74, 116-143. doi: 10.1016/j.biopsycho.2006.06.009

Porges, S. W. (2009). The polyvagal theory: new insights into adaptive reactions of the autonomic nervous system. Cleve. Clin. J. Med. 76, S86-S90. doi: $10.3949 /$ ccjm.76.s2.17

Porges, S., Davila, M., Lewis, G., Kolacz, J., Okonmah-Obazee, S., Hane, A., et al. (2019). Autonomic regulation of preterm infants is enhanced by family nurture intervention. Dev. Psychobiol. 61, 942-952. doi: 10.1002/dev.21841

Porges, S. W., Doussard-Roosevelt, J. A., Portales, A. L., and Greenspan, S. I. (1996). Infant regulation of the vagal 'Brake' predicts child behavior problems: a psychobiological model of social behavior. Dev. Psychobiol. 29, 697-712. doi: 10.1002/(SICI) 1098-2302(199612)29:8<697::AID-DEV5>3.0.CO;2-O

Quas, J. A., Hong, M., Alkon, A., and Boyce, W. T. (2000). Dissociations between psychobiologic reactivity and emotional expression in children. Dev. Psychobiol. 37, 153-175. doi: 10.1002/1098-2302(200011)37:3<153::aid$\operatorname{dev} 4>3.0 . \operatorname{co} ; 2-\mathrm{y}$

Quas, J. A., Yim, I. S., Oberlander, T. F., Nordstokke, D., Essex, M. J., Armstrong, J. M., et al. (2014). The symphonic structure of childhood stress reactivity: patterns of sympathetic, parasympathetic and adrenocortical responses to psychological challenge. Dev. Psychopathol. 26, 963-982. doi: 10.1017/s0954579414000480

Quinkert, A. W., Vimal, V., Weil, Z. M., Reeke, G. N., Schiff, N. D., Banavar, J. R., et al. (2011). Quantitative descriptions of generalized arousal, an elementary function of the vertebrate brain. Proc. Natl. Acad. Sci. U S A 108, 15617-15623. doi: 10.1073/pnas.1101894108

Reynolds, S., Lane, S. J., and Gennings, C. (2010). The moderating role of sensory overresponsivity in HPA activity: a pilot study with children diagnosed with ADHD. J. Atten. Disord. 13, 468-478. doi: 10.1177/1087054708 329906

Roberts, T., Stagnitti, K., Brown, T., and Bhopti, A. (2018). Relationship between sensory processing and pretend play in typically developing children. Am. J. Occup. Ther. 72, 7201195050p1-7201195050p8. doi: 10.5014/ajot.2018. 027623

Roder, E., Koehler-Dauner, F., Krause, S., Prinz, J., Rottler, E., Alkon, A., et al. (2020). Maternal separation and contact to a stranger more than reunion affect the autonomic nervous system in the mother-child dyad: ANS measurements during strange situation procedure in mother-child dyad. Int. J. Psychophysiol. 147, 26-34. doi: 10.1016/j.ijpsycho.2019.08.015

Rogers, S. J., and Ozonoff, S. (2005). Annotation: what do we know about sensory dysfunction in autism? A critical review of the empirical evidence. J. Child. Psychol. Psychiatry 46, 1255-1268. doi: 10.1111/j.1469-7610.2005.01431.x

Rotenberg, S., and McGrath, J. J. (2016). Inter-relation between autonomic and hpa axis activity in children and adolescents. Biol. Psychol. 117, 16-25. doi: 10.1016/j.biopsycho.2016.01.015

Roubinov, D. S., Bush, N. R., Hagan, M. J., Thompson, J., and Boyce, W. T. (2019). Associations between classroom climate and children's externalizing symptoms: the moderating effect of kindergarten children's parasympathetic reactivity. Dev. Psychopathol. 1-12. doi: 10.1017/S095457941900052X [Epub ahead of print].
Royeen, C. B., and Lane, S. J. (1991). "Tactile processing and sensory defensiveness," in Sensory Integration: Theory and Practice, eds G. Anne Fisher, A. Elizabeth Murray, C. Anita Bundy (Philadelphia: FA Davis), 108-136.

Salomon, K., Matthews, K. A., and Allen, M. T. (2000). Patterns of sympathetic and parasympathetic reactivity in a sample of children and adolescents. Psychophysiology 37, 842-849. doi: 10.1111/1469-8986.3760842

Sanislow, C. A., Ferrante, M., Pacheco, J., Rudorfer, M. V., and Morris, S. E. (2019). Advancing translational research using NIMH research domain criteria and computational methods. Neuron 101, 779-782. doi: 10.1016/j.neuron.2019. 02.024

Schaaf, R. C., Benevides, T., Blanche, E. I., Brett-Green, B. A., Burke, J. P., Cohn, E. S., et al. (2010). Parasympathetic functions in children with sensory processing disorder. Front. Integr. Neurosci. 4:4. doi: 10.3389/fnint.2010.00004

Schaaf, R. C., Benevides, T. W., Leiby, B. E., and Sendecki, J. A. (2015). Autonomic dysregulation during sensory stimulation in children with autism spectrum disorder. J. Autism Dev. Disord. 45, 461-472. doi: 10.1007/s10803-013-1924-6

Schaaf, R. C., Burke, J. P., Cohn, E., May-Benson, T. A., Schoen, S. A., Roley, S. S., et al. (2014). State of measurement in occupational therapy using sensory integration. Am. J. Occup. Ther. 68, e149-e153. doi: 10.5014/ajot.2014.012526

Schaaf, R. C., Dumont, R. L., Arbesman, M., and May-Benson, T. A. (2018). Efficacy of occupational therapy using ayres sensory integration ${ }^{\circledR}$ : a systematic review. Am. J. Occup. Ther. 72, 7201190010p1-7201190010p10. doi: 10.5014/ajot.2018.028431

Schaaf, R. C., Miller, L. J., Seawell, D., and O'Keefe, S. (2003). Children with disturbances in sensory processing: a pilot study examining the role of the parasympathetic nervous system. Am. J. Occup. Ther. 57, 442-449. doi: 10.5014/ajot.57.4.442

Schmahmann, J. D., Guell, X., Stoodley, C. J., and Halko, M. A. (2019). The theory and neuroscience of cerebellar cognition. Annu. Rev. Neurosci. 42, 337-364. doi: 10.1146/annurev-neuro-070918-050258

Schoen, S. A., Miller, L. J., Brett-Green, B. A., and Nielsen, D. M. (2009). Physiological and behavioral differences in sensory processing: a comparison of children with autism spectrum disorder and sensory modulation disorder. Front. Integr. Neurosci. 3:29. doi: 10.3389/neuro.07.029.2009

Shine, J. M., Breakspear, M., Bell, P. T., Ehgoetz Martens, K. A., Shine, R., Koyejo, O., et al. (2019). Human cognition involves the dynamic integration of neural activity and neuromodulatory systems. Nat. Neurosci. 22, 289-296. doi: 10.1038/s41593-018-0312-0

Shine, J., and Shine, R. (2014). Delegation to automaticity: the driving force for cognitive evolution? Front. Neurosci. 8:90. doi: 10.3389/fnins.2014.00090

Shonkoff, J. P., Garner, A. S., The Committee on Psychosocial Aspects of Child and Family Health, Committee on Early Childhood, Adoption, and Dependent Care, Section on Developmental and Behavioral Pediatrics, Siegel, B. S., et al. (2012). The lifelong effects of early childhood adversity and toxic stress. Pediatrics 129, e232-e246. doi: 10.1542/peds.2011-2663

Sinclair, D., Oranje, B., Razak, K. A., Siegel, S. J., and Schmid, S. (2017). Sensory processing in autism spectrum disorders and fragile $\times$ syndrome-from the clinic to animal models. Neurosci. Biobehav. Rev. 76, 235-253. doi: 10.1016/j. neubiorev.2016.05.029

Smith, J. D., Woodhouse, S. S., Clark, C. A. C., and Skowron, E. A. (2016). Attachment status and mother-preschooler parasympathetic response to the strange situation procedure. Biol. Psychol. 114, 39-48. doi: 10.1016/j.biopsycho. 2015.12.008

Su, C.-T., Wu, M.-Y., Yang, A.-L., Chen-Sea, M. J., and Hwang, I. S. (2010). Impairment of stance control in children with sensory modulation disorder. Am. J. Occup. Ther. 64, 443-452. doi: 10.5014/ajot.2010.09074

Thayer, J. F., and Lane, R. D. (2000). A model of neurovisceral integration in emotion regulation and dysregulation. J. Affect. Disord. 61, 201-216. doi: 10.1016/s0165-0327(00)00338-4

Tops, M., Quirin, M., Boksem, M. A. S., and Koole, S. L. (2017). Largescale neural networks and the lateralization of motivation and emotion. Int. J. Psychophysiol. 119, 41-49. doi: 10.1016/j.ijpsycho.2017.02.004

Torres, E. B., and Whyatt, C. (2018). Autism: The Movement Sensing Perspective. Boca Raton, FL: CRC Press.

Van Ryzin, M. J., Chatham, M., Kryzer, E., Kertes, D. A., and Gunnar, M. R. (2009). Identifying atypical cortisol patterns in young children: the benefits of groupbased trajectory modeling. Psychoneuroendocrinology 34, 50-61. doi: 10.1016/j. psyneuen.2008.08.014 
Wiley, J. F., Gruenewald, T. L., Karlamangla, A. S., and Seeman, T. E. (2016). Modeling multisystem physiological dysregulation. Psychosom. Med. 78, 290-301. doi: 10.1097/psy.00000000000 00288

Wittenborn, A. K., Rahmandad, H., Rick, J., and Hosseinichimeh, N. (2016). Depression as a systemic syndrome: mapping the feedback loops of major depressive disorder. Psychol. Med. 46, 551-562. doi: 10.1017/ s0033291715002044

Wu, D., José, J. V., Nurnberger, J. I., and Torres, E. B. (2018). A biomarker characterizing neurodevelopment with applications in autism. Sci. Rep. 8:614. doi: 10.1038/s41598-017-18902-w
Conflict of Interest: The authors declare that the research was conducted in the absence of any commercial or financial relationships that could be construed as a potential conflict of interest.

Copyright (c) 2020 Christensen, Wild, Kenzie, Wakeland, Budding and Lillas. This is an open-access article distributed under the terms of the Creative Commons Attribution License (CC BY). The use, distribution or reproduction in other forums is permitted, provided the original author(s) and the copyright owner(s) are credited and that the original publication in this journal is cited, in accordance with accepted academic practice. No use, distribution or reproduction is permitted which does not comply with these terms. 